\title{
Ameliorative Effect of Carob Pods Extract (Ceratonia siliqua L.) against Cyclophosphamide Induced Alterations in Bone Marrow and Spleen of Rats
}

\author{
Sawsan Ahmed Abd Elhalim ${ }^{1}$, Hayat Mohamed Sharada ${ }^{1}$, Ibrahim Abulyazid ${ }^{2}$, Wael Mahmoud Aboulthana ${ }^{3 *}$, \\ Sohaila Talaat Abd Elhalim ${ }^{1}$ \\ ${ }^{1}$ Chemistry Department, Faculty of Science, Helwan University, Cairo, Egypt. ${ }^{2}$ Biological Application Department, Atomic Energy Authority, Egypt. \\ ${ }^{3}$ Biochemistry Department, Genetic Engineering and Biotechnology Division, National Research Centre, 33 Bohouth St., P.O. 12622, Dokki, Giza, Egypt.
}

\begin{tabular}{|c|c|}
\hline ARTICLE INFO & ABSTRACT \\
\hline $\begin{array}{l}\text { Article history: } \\
\text { Received on: } 25 / 07 / 2017 \\
\text { Accepted on: 08/09/2017 } \\
\text { Available online: } 30 / 10 / 2017\end{array}$ & $\begin{array}{l}\text { Cyclophosphamide (CYP) belongs to the anticancer drugs that exhibit potentially life-threatening effects on the } \\
\text { immune and hematopoietic systems. The study aimed to assess efficiency of carob pods extract against the } \\
\text { adverse CYP effect on spleen and lymphatic tissues which are the most sensitive components of immune } \\
\text { system. In the present study, the hematological indices and markers of oxidative stress were assessed. In }\end{array}$ \\
\hline $\begin{array}{l}\text { Key words: } \\
\text { Cyclophosphamide, Bone } \\
\text { marrow, Spleen, Ceratonia } \\
\text { siliqua, Electrophoresis, } \\
\text { Isoenzymes. }\end{array}$ & $\begin{array}{l}\text { (GPx), } \alpha-\text { and } \beta \text { - esterase (EST) isoenzymes and genomic DNA patterns were electrophoretically detected in } \\
\text { both of bone marrow and spleen tissues. It was verified that CYP caused significant }(\mathrm{P}<0.05) \text { decline in the } \\
\text { hematological measurements which restored in all carob treated groups. Furthermore, all native electrophoretic } \\
\text { patterns and isoenzymes in the bone marrow and spleen tissues illustrated that the lowest similarity index (SI \%) } \\
\text { was noticed in the CYP-treated group. The carob extract increased the SI \% through restoring the absent normal } \\
\text { bands and hiding the abnormal ones in all carob treated groups. Moreover, CYP induced cleavage of the } \\
\text { genomic DNA and the carob extract maintained integrity of the genomic DNA in spleen tissue. }\end{array}$ \\
\hline
\end{tabular}

\section{INTRODUCTION}

Many anticancer drugs exhibit potentially lifethreatening effects on the immune and hematopoietic systems (Ryu et al., 2007). The treatment by mean of chemotherapy is effective for treating many cancerous tumors although it exhibits adverse effects on normal cells. In particular, this treatment may destroy hematopoietic stem cells, thereby inducing severe side effects, such as anemia and leukopenia. For this reason, the individuals who obey these types of treatments are susceptible to

\footnotetext{
* Corresponding Author

Wael Mahmoud Aboulthana, Biochemistry Department, Genetic

Engineering and Biotechnology Division, National Research Centre,

33 Bohouth St., Dokki, Giza, Egypt. Tel:+201124582973;

E-mail:wmkamel83@hotmail.com
}

higher risk for viral or bacterial infections (Wang et al., 2002 ; Vadhan-Raj, 2009). Anemia is one of the most common side effects of chemotherapy. It occurred in approximately $70-90 \%$ of the patients who undergo this kind of treatment (Groopman and Itri, 1999). Therefore, increasing attention is being paid to combining chemotherapy with treatments that stimulate the immune and hematopoietic systems. In this regard, the researchers directed to search in the nature to find active biological constituents suitable to possess antioxidant activity and stimulate the immune systems with relatively few or without deleterious side effects (Ryu and Kim, 2005). It is well known that cyclophosphamide (CYP) belongs to the nitrogen mustard subclass of alkylating agents that cause serious damage to components of the immune and hematopoietic systems leading to a notable reduction in leukocytes (Angulo et al., 2000). 
Spleen, thymus and lymphatic system are the most important components of the immune system which are affected by intraperitoneal CYP injection (McKallip et al., 2002). CYP is effective chemotherapeutic agent and widely used effectively to treat lymphoma, leukemia and solid cancers. Toxicity of the bone marrow and immunosuppression are considered as the most common side effects of CYP. In turn, toxicity of the bone marrow leads subsequently to further hematopoietic dysfunction, which represented by anemia, leukopenia and thrombocytopenia (Vadhan-Raj, 2009).

It was emphasized that the CYP administration exhibited toxicity, in a dose-dependent manner, in blood cells and bone marrow of rats (Ayhanci et al., 2009). It was reported that CYP exhibits large immunotoxic effects on the blood lymphocytes which may be more sensitive indicator of immunotoxic effects than spleen lymphocytes (Nygaard and Løvik, 2002). It has also been reported that CYP pretreatment rapidly decreased the activity of all lymphoid tissue (Ben-Hur et al., 2002). It inhibits development of diabetes by inhibiting development of insulitis through induction of immunoregulatory cell activity and suppression of cytokines that promote differentiation of Thl cell in rats (Sobel et al., 2000).

The native protein pattern in the nuclear matrix varies in a tissue-specific manner and change as cells differentiate (Zhao et al., 2006). Structural and functional components of the nuclear matrix are targets for the alkylating chemotherapeutic agents mainly the CYP that interacts with proteins of the nuclear matrix and with DNA close to transcription sites and matrix-bound replication (Fernandes and Catapano, 1995; Muenchen and Pienta, 1999). In 2007, Codrington et al. (2007) used proteomic strategies during their experimental studies to identify the native proteins and to elucidate effects of chronic CYP exposure on expression of these proteins.

It is well known that the environmental conditions in the Mediteranean regions are suitable for growth of Ceratonia silique. The crude carob pods extract appeared with antioxidant properties higher than certain known polyphenols such as catechin, quercetin and gallic acid alone (Kumazama et al., 2002; Makris and Kefalos, 2004). It was revealed that the aqueous carob pod extract exerted anxiolytic-sedative effects and act as a chemopreventive agent (Avallone et al., 2002).

The aqueous carob extract exhibited antiproliferative and antioxidative efficiency against cancerous cells that grow and increase rapidly. This is mostly related to presence of high content of the polyphenolic compounds. In addition, presence of carotenoids can enhance the antioxidant capacity, which may suggest a synergistic effect between polyphenols and carotenoid compounds in the carob pods extract (Abdul Karim and Azlan, 2012).

Therefore, aim of the present study was to describe the possible differences in the different electrophoretic patterns occurred in the bone marrow and spleen tissues as a result of CYP administration and to evaluate the ameliorative effect of aqueous carob pod extract against these abnormalities in rats.

\section{MATERIALS AND METHODS}

Preparation and administration of the aqueous carob extract

The mature carob pods were dried in an incubator at 50 ${ }^{\circ} \mathrm{C}$ for $72 \mathrm{~h}$. The dried plant material was crushed into powder in an electric blender and dissolved in nanopure water. The aqueous carob extract was administrated orally by stomach tube at the dose $1 / 10$ of $\mathrm{LD}_{50}$ equivalent to $2 \mathrm{~g} / \mathrm{kg}$ b.w. according to the experiment carried out by Rtibi et al. (2015).

\section{Animals and treatments}

Healthy thirty six adult male Wistar rats (weighting 120 $150 \mathrm{~g}$ ) were housed in six per cage. The animals were provided with water ad libitum and standard food and maintained under normal environmental conditions at $25 \pm 2{ }^{\circ} \mathrm{C}$.

\section{Ethics Statement}

The experimental design and animal handling were performed according to the experimental protocol which was approved by Institutional Animal Ethics Committee of National Research Centre, Dokki, Giza, Egypt and were conducted in accordance with guidelines as per "Guide for the care and use of laboratory animal" and with permission from Committee for the Purpose of Control and Supervision of Experiments on Animals.

\section{Experimental Design}

The rats were randomly divided into six groups. Group I (Control group): Rats were fed with normal diet as ad libitum and received distilled water for 7 days. Group II (Carob extract treated group): Rats were fed with normal diet associated with the treatment with aqueous carob extract for 7 days. Group III (CYPtreated group): Rats were treated with CYP only interperitoneally (i.p.) at a dose equivalent to $0.3 \mathrm{mg} / \mathrm{kg}$ body weight for 7 days as mentioned by Patel et al. (2012). Group IV (Simultaneous treated group): Rats received CYP i.p. and administrated with carob extract in parallel manner for 7 days. Group V (Pre-treated group): Rats were administrated with carob extract for 7 days and followed by receiving CYP i.p. for another 7 days. Group VI (Post-treated group): Rats received CYP i.p. for 7 days then treated with carob extract for another 7 days.

\section{Collection of samples}

Seven days after the experimental period (i.e., on the $8^{\text {th }}$ day), all the animals were anaesthetized. Blood was collected from retro orbital plexus of the animals into heparinized tubes for the hematological measurements. The rats were sacrificed by cervical dislocation. All the bone marrow samples were taken according to method described by Schwenke et al. (1994) who documented that bone marrow was flushed out of the medullary cavity of femora with an ice-cold Tris buffer $(\mathrm{pH}$ 7.5). Ten milliliters of a bone marrow suspension was homogenized at $4{ }^{\circ} \mathrm{C}$ using a Teflon homogenizer. Furthermore, the spleen tissues were excised and washed in ice-cold saline then homogenized in $0.01 \mathrm{M}$ Tris $-\mathrm{HCl}$ buffer ( $\mathrm{pH}$ 7.4). Aliquots of this homogenate were used for 
measuring markers of the oxidative stress and for the different electrophoretic patterns.

\section{Haematological analysis}

The blood was analyzed on an automatic blood analyzer (XE 2100 D; Sysmex, Kobe, Japan) to quantify hemoglobin (HB), red blood cells (RBCs), hematocrit (HCT), corpuscular volume (MCV), mean corpuscular haemoglobin $(\mathrm{MCH})$, mean corpuscular haemoglobin concentration (MCHC), platelets, white blood cells (WBCs) and differential blood cells (lymphocytes, neutrophils, monocytes and eosinophils).

\section{Markers of the oxidative stress}

The lipid peroxidation (LPO) product was determined in the spleen and bone marrow homogenates spectrophotometrically at wave length $535 \mathrm{~nm}$ using a UV-vise spectrophotometer (Shimadzu uv-2401 pc) according to method suggested by Ohkawa et al. (1979). The total antioxidant capacity (TAC) was assayed colorimetrically in these tissues based on capacity of the sample to inhibit production of thiobarbituric acid reactive substances from sodium benzoate under the influence of the free oxygen radicals derived from Fenton's reaction as mentioned by Koracevic et al. (2001).

\section{Statistical Analysis}

All the grouped data were statistically evaluated by the Statistical Package for Social Sciences (SPSS for windows, version 11.0). The results were expressed as mean \pm standard error (SE). Significant difference between the groups were statistically analyzed by one-way analysis of variance test (one-way ANOVA) followed by Bonferoni test. A "P" value of less than 0.05 was considered to indicate statistical significance.

\section{Histopathological examination}

After sacrifice, autopsy samples were taken from spleen tissues of different groups and immediately fixed in $10 \%$ formal saline for $24 \mathrm{hr}$. The tissues were washed in tap water then dehydrated in serial dilutions of alcohol solutions. Tissue fragments were cleared in xylene and embedded in paraffin then used for histopathological examination. Paraffin bees wax tissue blocks were prepared for sectioning at 4 microns thickness by sledge microtome. The tissue sections were collected on glass slides and deparaffinized then stained by hematoxylin and eosin (H\&E) stain for examination through the light electric microscope (Banchroft et al., 1996). The histopathological changes were scored according to Dommels et al. (2007). A rating score between 0 (no damage) and +++ (maximal damage) was assigned for each investigated section. Sections from at least five rats were carefully investigated.

\section{Electrophoretic patterns}

The tissues (spleen and bone marrow) were frozen rapidly with liquid nitrogen and ground then homogenized in $1 \mathrm{ml}$ water-soluble extraction buffer. The homogenates were centrifuged at $10,000 \mathrm{rpm}$ at $4^{\circ} \mathrm{C}$ for $15 \mathrm{~min}$. The supernatants containing water-soluble proteins were transferred to new eppendorf tubes. Samples of each group were pooled together and used as one sample. Protein concentration was estimated in all pooled samples according to method of Bradford (1976) using bovine serum albumin as standard. Quantities of protein must be equal in all wells during all electrophoretic assays.

As documented by Laemmli (1970), the polyacrylamide gel electrophoresis was carried out using Mini-gel electrophoresis (BioRad, USA) at the concentration $10 \%$ but with the modification that samples, gels and running buffers were lacking sodium dodecyl sulphate (Darwesh et al., 2015). The native gels were consisting of Acrylamide/Bis $(30 \% \quad \mathrm{~T}, 2.67 \% \quad \mathrm{C})$ (Acrylamide: bis-acrylamide $=29.2: 0.8$ ) and $10 \%$ glycerol. The gel was run in buffer containing Tris (24 mM) and glycine (194 $\mathrm{mM}$ ). Bands of the native protein were visualized by staining with Coomassie Brilliant Blue G-250. The relative mobility (Rf) and band percent (B \%) of the electrophoretically separated proteins were determined in addition to the molecular weight (Mwt) which was estimated in comparison to marker of standard molecular weights with regularly spaced bands ranging from 6.458 to 195.755 KDa. Furthermore, the native gels were stained by mean of isoelectrophoresis for lipids and calcium moieties with Sudan Black B (SBB) (Subramaniam and Chaubal, 1990) and Alizarin Red 'S' (Zacharia and Kakati, 2004), respectively.

\section{Electrophoretic localization of in-gel enzyme activity}

The non-denaturing gel was stained for electrophoretic catalase (CAT) pattern according to method of Siciliano and Shaw (1976). It was stained for the electrophoretic peroxidase (GPx) pattern using benzidine stain prepared according to method described by Rescigno et al. (1997).

It was processed for localization of in-gel $\alpha$ - and $\beta$ esterase (EST) activities according to method modified recently by Ahmad et al. (2012) who postulated that the gel was incubated in reaction mixture containing $\alpha, \beta$-naphthyl acetate (5.58 X $\left.10^{-3} \mathrm{mM}, \mathrm{pH} 7.5\right)$ as substrates along with dye coupler Fast Blue RR.

\section{Genomic DNA Fragmentation}

The genomic DNA was extracted from spleen tissues using method mentioned by Barker et al. (2004). The polymerase chain reaction was carried out according to method described by Rapley (1998) for amplification of the genomic DNA with 8 random primers of different nucleotide sequences (OPA-04 (5'AATCGGGCTG-3'), OPA-05 (5'-AGGGGTCTTG-3'), OPA-07 (5'-GAAACGGGTG-3'), OPA-10 (5'-GTGATCGCAG-3'), OPA11 (5'-CAATCGCCGT-3'), OPA-12 (5'-TCGGCGATAG-3'), OPA-14 (5'-TCTGTGCTGG-3') and OPA-15 (5'-TTCCGAACCC$\left.3^{\prime}\right)$ ). The amplification process was carried out using DNA thermal cycler (Progeny 30, Techno, Cambridge Ltd. Dux ford Cambridge, UK) through the thermal program initial denaturation at $94^{\circ} \mathrm{C}$ for 5 min. followed by 40 cycles of DNA amplification. Each cycle was consisting of denaturation at $94{ }^{\circ} \mathrm{C}$ for $2 \mathrm{~min}$. then annealing at 
$40{ }^{\circ} \mathrm{C}$ for $2 \mathrm{~min}$. and extension at $72^{\circ} \mathrm{C}$ for $7 \mathrm{~min}$. The amplified fragments were separated on $2 \%$ agarose gel, visualized on a UV transilluminator and photographed by Gel Documentation System then analyzed in comparison to DNA molecular weight marker (HyperLadder II) with regularly spaced bands ranging from $50 \mathrm{bp}$ to $2000 \mathrm{bp}$.

\section{Data analysis}

The native bands in polyacrylamide gel and the DNA fragments in agarose gel were analyzed using Quantity One software (Version 4.6.2). Percent of the similarity index (SI \%) was calculated according to equation suggested by Nei and $\mathrm{Li}$ (1979) to compare all treated groups to control group.

\section{RESULTS}

\section{Haematological study}

As revealed in Fig. 1, CYP caused significant $(\mathrm{P}<0.05)$ decline in all hematological measurements (HB, RBCs, HCT, $\mathrm{MCV}, \mathrm{MCH}, \mathrm{MCHC}$, platelets, WBCs and the differential blood cells (lymphocytes, neutrophils, monocytes and eosinophils)). Carob extract increased levels of these measurements significantly
$(\mathrm{P}<0.05)$ in all carob treated groups (especially in the simulttreated group) and restored their levels to normalcy.

\section{Oxidative stress}

Data in Fig. 2 emphasized that CYP exerted significant $(\mathrm{P}<0.05)$ elevation in the LPO level associated with significant $(\mathrm{P}<0.05)$ decline in the TAC level in both of bone marrow and spleen tissue homogenates. Carob extract lowered the LPO level significantly $(\mathrm{P}<0.05)$ and restored the TAC level to normal value in all carob treated groups.

\section{Histopathological study}

As illustrated in Fig. 3a, normal histological structure of white (W) and red pulps (R) was recorded in spleen of control group. In carob extract treated group (Fig. 3b), no histopathological abnormalities were noticed. On the contrary in the CYP-treated group (Fig. 3c), ischaemia and fibrosis were detected in the red pulps $(\mathrm{R})$ with moderate severity degree $(++$; 50-75\%). No histopathological alterations were detected in the simult-treated group (Fig. 3d). In the pre-treated and post-treated groups (Fig. 3e \&f), no severe or deleterious alterations were observed but there was hemosiderosis in diffuse manner all over the red pulps $(\mathrm{R})$ with mild severity degree $(+; 25-50 \%)$.

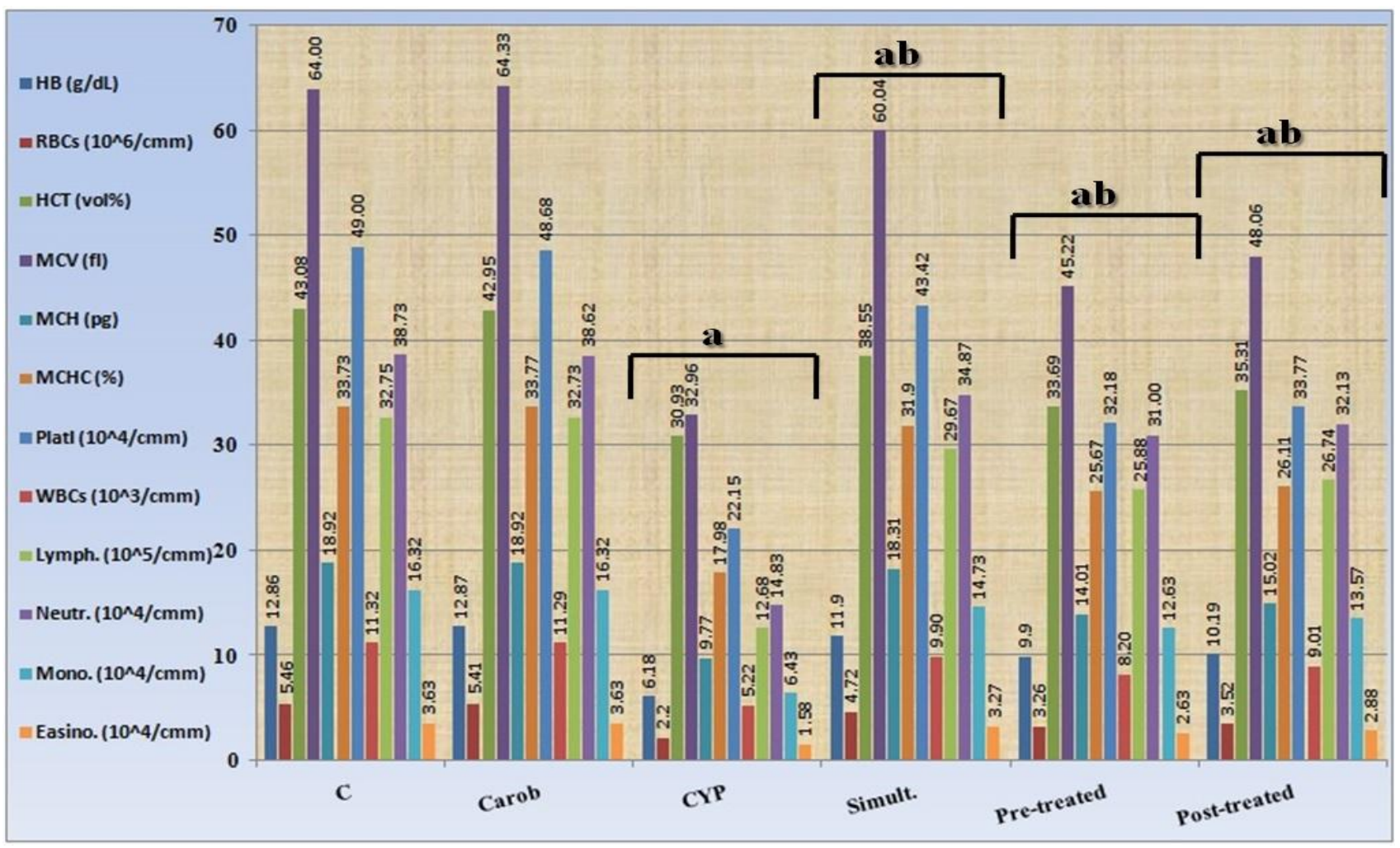

Fig. 1: Effect of carob extract against cyclophosphamide induced changes in different hematological measurements. a: values compared to control group ; b: values compared to CYP-treated group (significant $\mathrm{p}<0.05$ ). 
a)

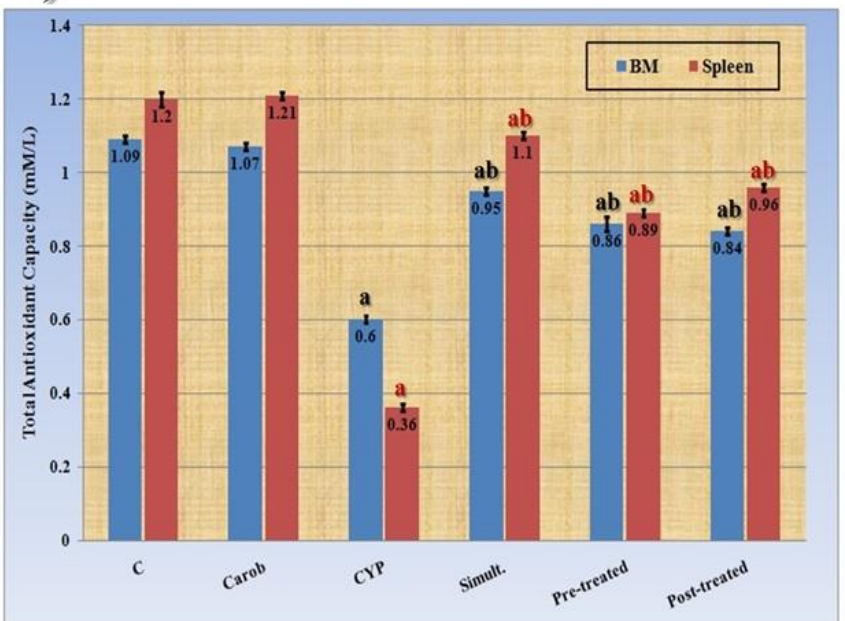

b)

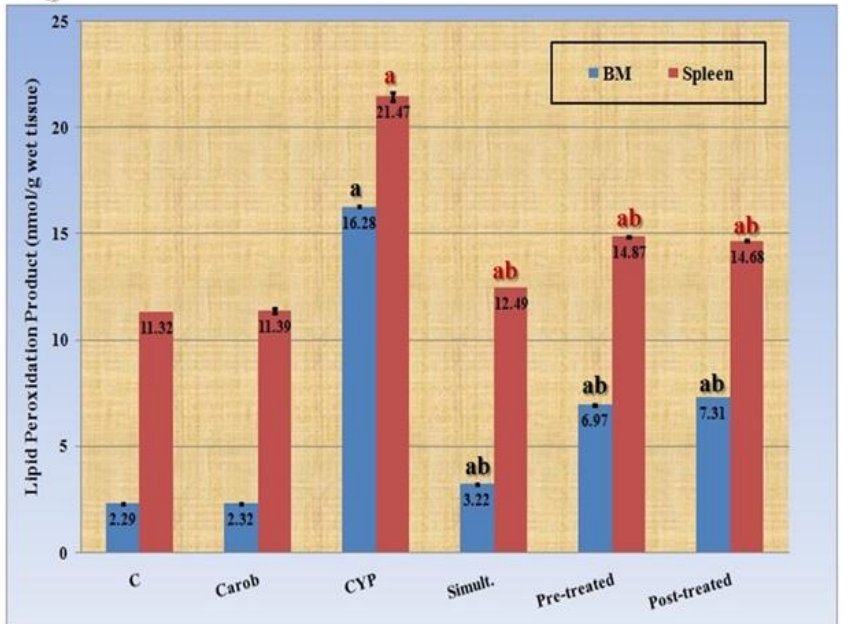

Fig. 2: Effect of carob extract against cyclophosphamide induced alterations in markers of the oxidative stress: a) lipid peroxidation (LPO) product and b) total antioxidant capacity (TAC) level in bone marrow and spleen tissue. Values inside columns are expressed as mean. a shows the significance in comparison to the control group and $b$ shows the significance in comparison to CYP-treated group (significant $p<0.05$ ).
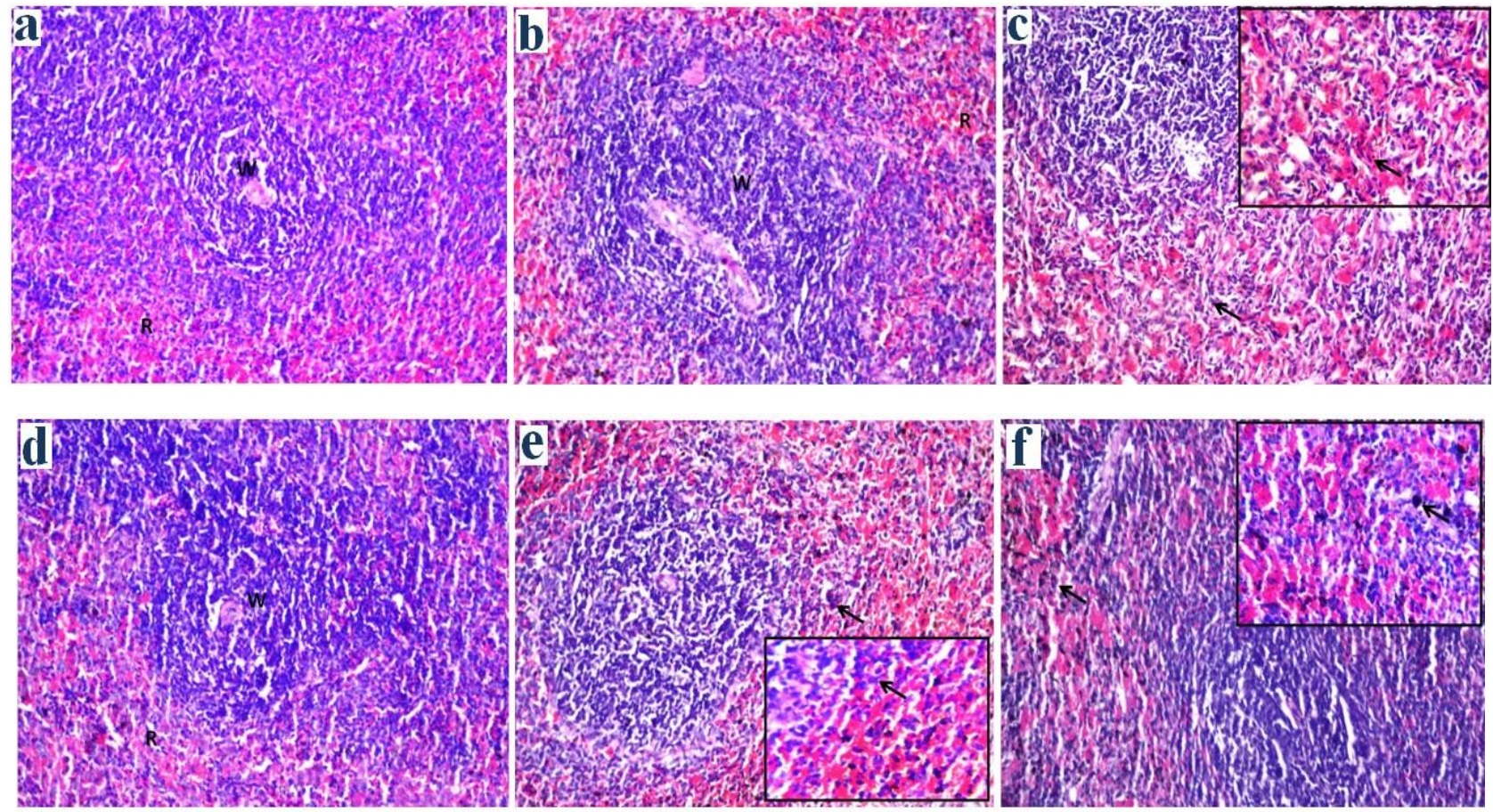

Fig. 3: Spleen tissue showing a) control group with normal histological structure of the white (W) and red (R) pulps (H\&E, X 40), b) carob treated group without deviation from normal histological structure (H\&E, X 40), c) CYP-treated group identifying ischemia and fibrosis (black arrow) in red (R) pulps (H\&E, X 80), d) simult-treated group with normal histological structure (H\&E, X 40), e) pre-treated group showing presence of hemosiderosis in red (R) pulps (black arrow) (H\&E, X 80) and f) post-treated group with hemosiderosis in red (R) pulps (black arrow) (H\&E, X 80).

\section{Native electrophoretic patterns}

The electrophoretic protein pattern in bone marrow (Fig. 4a) showed that 3 common bands were identified at Rfs 0.63 , 0.93 and 0.97 (Mwts 17.20, 6.81 and $5.78 \mathrm{KDa}$, respectively). In addition, 2 characteristic bands were identified in the CYP-treated group at Rf 0.26 and 0.77 (Mwts 58.47 and $12.62 \mathrm{KDa}$ ). CYP caused qualitative abnormalities represented by disappearance of 4 normal bands with appearance of 4 abnormal bands at Rfs 0.26 , 0.45, 0.71 and 0.77 (Mwts 58.47, 24.99, 15.33 and 12.62 KDa). The lowest SI \% value was noticed in the CYP-treated group $(42.86 \%)$. While in the simult-treated, pre-treated and post-treated groups, the SI \% values were represented by $76.92,71.43$ and 80.00 , respectively. Furthermore, the electrophoretic lipoprotein pattern (Fig. $4 \mathrm{~b}$ ) illustrated that 4 common bands were identified at 
Rfs $0.09,0.59,0.97$ and 0.99 (B \% 17.11, 15.78, 12.07 and 12.24, respectively) associated with the characteristic band which was noticed in CYP-treated group at Rf 0.46 and B \% 18.41. CYP caused qualitative disturbances represented by disappearance of 3 normal bands with notification of 2 abnormal bands at Rfs 0.32 and 0.46 (B \% 18.87 and 18.41). In addition, it caused quantitative alteration represented by enhancing quantity of the band identified at $\operatorname{Rf} 0.59$ (B \% 23.47).

The lowest SI \% was noticed in the CYP-treated group $(61.54 \%)$. Carob extract increased the SI \% values in the simulttreated, pre-treated and post-treated groups (85.71, 92.31 and 92.31, respectively). The electrophoretic calcium moiety of native protein pattern revealed that 2 common bands were identified at Rfs 0.03 and 0.96 (B \% 20.37 and 18.13, respectively) associated with 3 characteristic bands in CYP-treated group at Rfs $0.13,0.26$ and 0.58 (B \% 18.66, 20.23 and 20.63, respectively). CYP caused disturbances represented by disappearance of 3 normal bands with existence of the 3 characteristic bands. The lowest SI \% value was observed in CYP-treated group (SI \% 40.00). It reached the highest value $(100.00 \%)$ in all carob treated groups (Fig. 4c).

The electrophoretic protein pattern in spleen tissue (Fig. 5a) showed that 5 common bands were identified at Rfs $0.07,0.56$,
0.69, 0.85 and 0.95 (Mwts 176.49, 18.97, 15.44, 8.44 and 5.45 $\mathrm{KDa}$, respectively). In addition, one characteristic band was noticed at Rf 0.44 (Mwt 25.72 KDa) in the CYP-treated group. CYP caused qualitative abnormalities represented by disappearance of 3 normal bands with appearance of the characteristic band. The SI \% in CYP-treated group (71.43\%) was lower than that in all carob treated groups (100.00\%). The electrophoretic lipoprotein pattern (Fig. 3b) illustrated that 3 common bands identified at Rfs $0.23,0.66$ and 0.98 (B \% 22.29, 22.29 and 17.98, respectively). In addition, one characteristic band was noticed in CYP-treated group at Rf 0.15 (B \% 29.13). CYP caused qualitative disturbances represented by disappearance of 2 normal bands with presence of the characteristic band. The SI \% in CYP-treated group $(66.67 \%)$ was lower than that in all carob treated groups $(100.00 \%)$. As revealed in Fig. 5b, the electrophoretic calcium moiety of native protein pattern revealed that 4 common bands were identified at Rfs $0.09,0.21,0.31$ and 0.56 (B \% 21.01, 18.49, 21.01 and 21.01, respectively) with notification of one characteristic band at $\mathrm{Rf} 0.04$ (B \% 19.01) in CYP-treated group. CYP caused disturbances represented by disappearance of one normal band in addition to appearance of the characteristic band. The SI \% in CYP-treated group (80.00\%) was less than that in all carob treated groups $(100.00 \%)$.

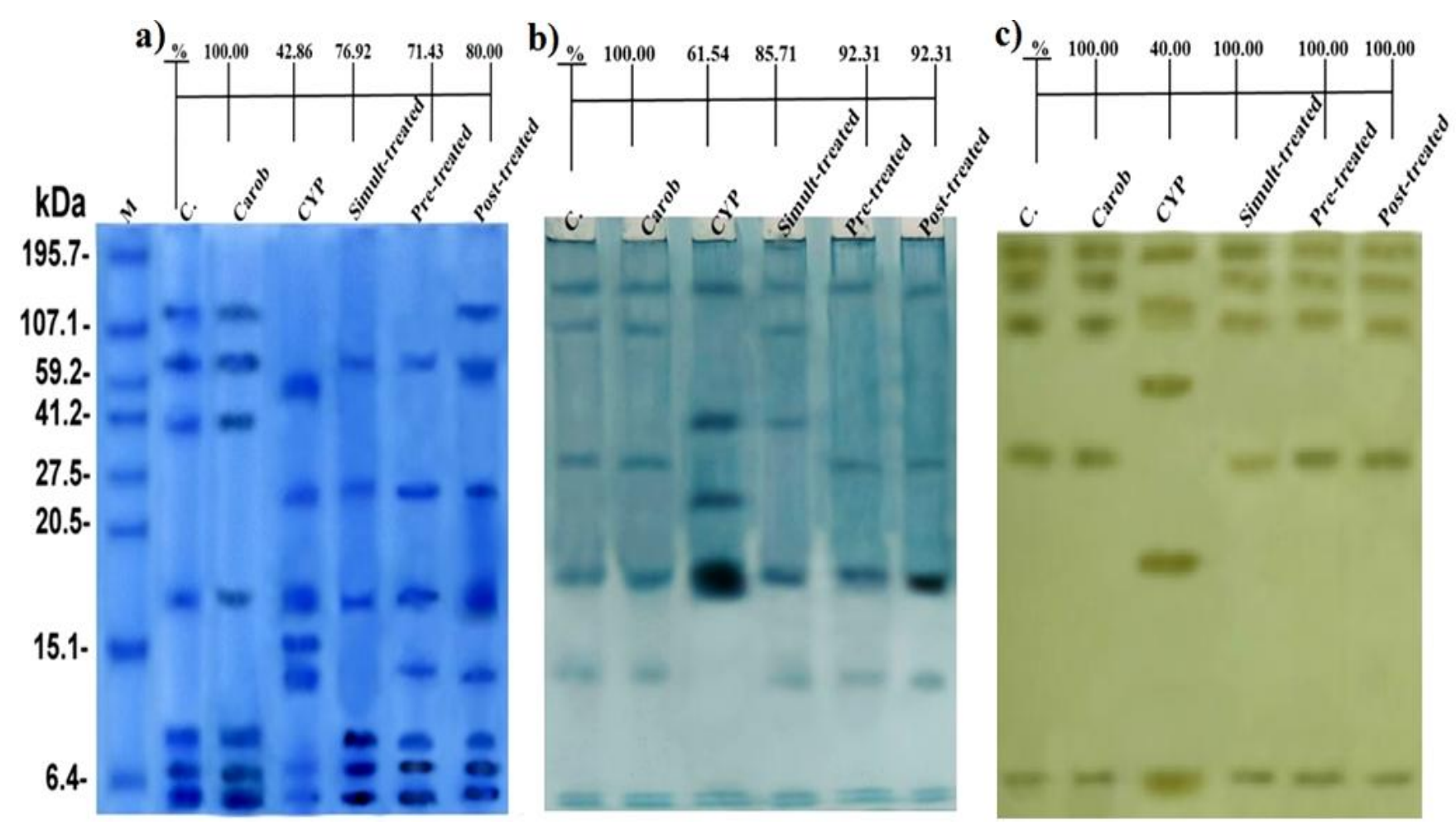

Fig. 4: Electrophoretic patterns showing the curative effect of aqueous carob extract against cyclophosphamide induced alterations on a) native protein, b) lipoprotein and c) calcium moieties of the native protein in bone marrow of rats. 


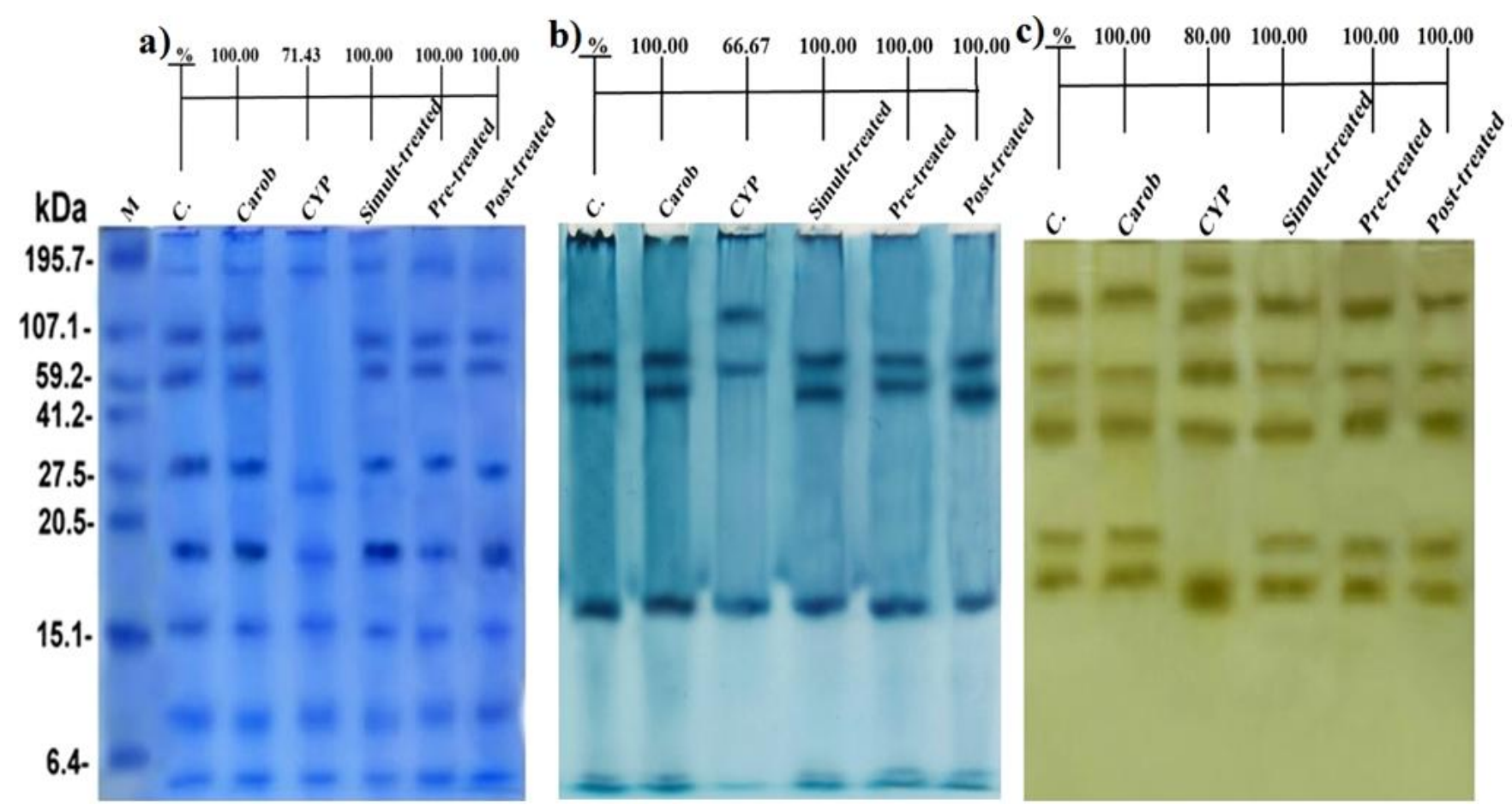

Fig. 5: Electrophoretic patterns showing the curative effect of aqueous carob extract against cyclophosphamide induced alterations on a) native protein, b) lipoprotein and c) calcium moieties of the native protein in spleen tissue of rats.

\section{Electrophoretic isoenzymes}

As revealed in the electrophoretic CAT pattern in bone marrow (Fig. 6a), there was one common band identified at Rf 0.87 (B \% 32.80) associated with 2 characteristic bands at Rfs 0.43 and 0.74 (B \% 33.91 and 33.91, respectively) in CYP-treated group. CYP caused alterations represented by disappearance of 2 normal bands in addition to appearance of the characteristic bands. The SI \% was represented by the lowest value $(33.33 \%)$ in the CYP-treated group. The carob extract increased the SI \% value (100.00) in all carob treated groups through restoring all the absent bands. As illustrated in Fig. 6b, the electrophoretic GPx pattern showed that 3 common bands were identified at Rfs $0.10,0.19$ and 0.63 (B \% 14.79, 15.92 and 18.62, respectively). Moreover, there were 4 characteristic bands at Rfs $0.05,0.34,0.39$ and 0.73 (B \% 14.09, 14.09, 14.09 and 14.09, respectively) in CYP-treated group. CYP caused disappearance of 3 normal bands with existence of the characteristic bands. The SI \% was represented by the lowest value $(46.15 \%)$ in the CYP-treated group. It reached the highest value (100.00) in all carob treated groups.

In spleen tissue, the electrophoretic CAT pattern (Fig. 7a) presented that one common band was identified at $\operatorname{Rf} 0.21$ (B \% 16.13) associated with 3 characteristic bands identified at Rfs 0.06 , 0.36 and 0.53 (B \% 22.51, 32.12 and 22.51, respectively) in CYPtreated group. CYP caused alterations represented by disappearance of 5 normal bands in addition to appearance of the characteristic bands. The lowest SI \% value was noticed in the CYP-treated group (20.00\%). The carob extract increased the SI $\%$ value in all carob treated groups $(100.00 \%)$ by regaining the absent normal bands. The electrophoretic GPx pattern (Fig. 7b) illustrated that 3 common bands were identified at 0.03, 0.58 and 0.70 (B \% 15.60, 19.83 and 22.33, respectively). Furthermore, there was one characteristic band at Rf 0.29 (B \% 24.66) in CYPtreated group. CYP exhibited mutagenic effect represented by disappearance of 2 normal bands in addition to presence of the characteristic band. The SI \% the CYP-treated group (66.67\%) was lower than that in all carob treated groups (100.00).

As illustrated in Fig. 8a, identification of $\alpha$-EST pattern in the bone marrow showed that 5 common bands were identified at Rfs $0.05,0.11,0.17,0.52$ and 0.62 (B \% 21.94, 21.68, 19.32, 11.48 and 10.43, respectively) associated with appearance of one characteristic band at Rf 0.35 (B \% 18.80) in CYP-treated group. CYP caused quantitative mutation represented by changing the $\mathrm{B}$ $\%$ of some qualitatively normal bands. The lowest SI \% (66.67\%) was noticed with the CYP-treated group. While with all carob treated groups, it reached the highest value (100.00). The electrophoretic $\beta$-EST pattern (Fig. 8b) showed that all bands in the control group are considered as common bands. One characteristic band was identified at Rf 0.23 (B \% 12.88) in CYPtreated group. CYP caused quantitative alterations represented by changing B \% of some qualitatively normal bands. This was in addition to the qualitative alteration which was represented by presence of the characteristic band. The SI \% value in the CYPtreated group $(90.91 \%)$ was less than that in all carob treated groups (100.00).

The electrophoretic $\alpha$-EST pattern in spleen tissue (Fig. 9a) verified the presence of 2 common bands at Rfs 0.52 and 0.63 
(B \% 33.12 and 33.77, respectively) associated with 3 characteristic bands at $\mathrm{R}_{\mathrm{f}} 0.27,0.39$ and 0.86 (B \% 20.36, 20.36 and 17.19, respectively) in CYP-treated group. CYP exhibited qualitative alterations represented by disappearance of one normal band in addition to presence of the characteristic bands. Furthermore, it caused quantitative mutation represented by decreasing B \% of 2 qualitatively normal bands. The lowest SI \% (50.00 \%) was noticed with the CYP-treated group. The carob extract increased the SI \% value in all carob treated groups
(100.00). The electrophoretic $\beta$-EST pattern (Fig. 9b) showed that number and arrangement of the bands were identical in all groups except the CYP-treated group. CYP caused severe qualitative abnormalities represented by disappearance of all normal bands with existence of one abnormal characteristic band (Rf 0.31 and $\mathrm{B}$ $\%$ 100.00). In the CYP-treated group, the SI \% value reached the lowest value $(00.00 \%)$. The carob extract increased the SI \% value in all carob treated groups (100.00) through restoring all absent bands and hiding the abnormal ones.

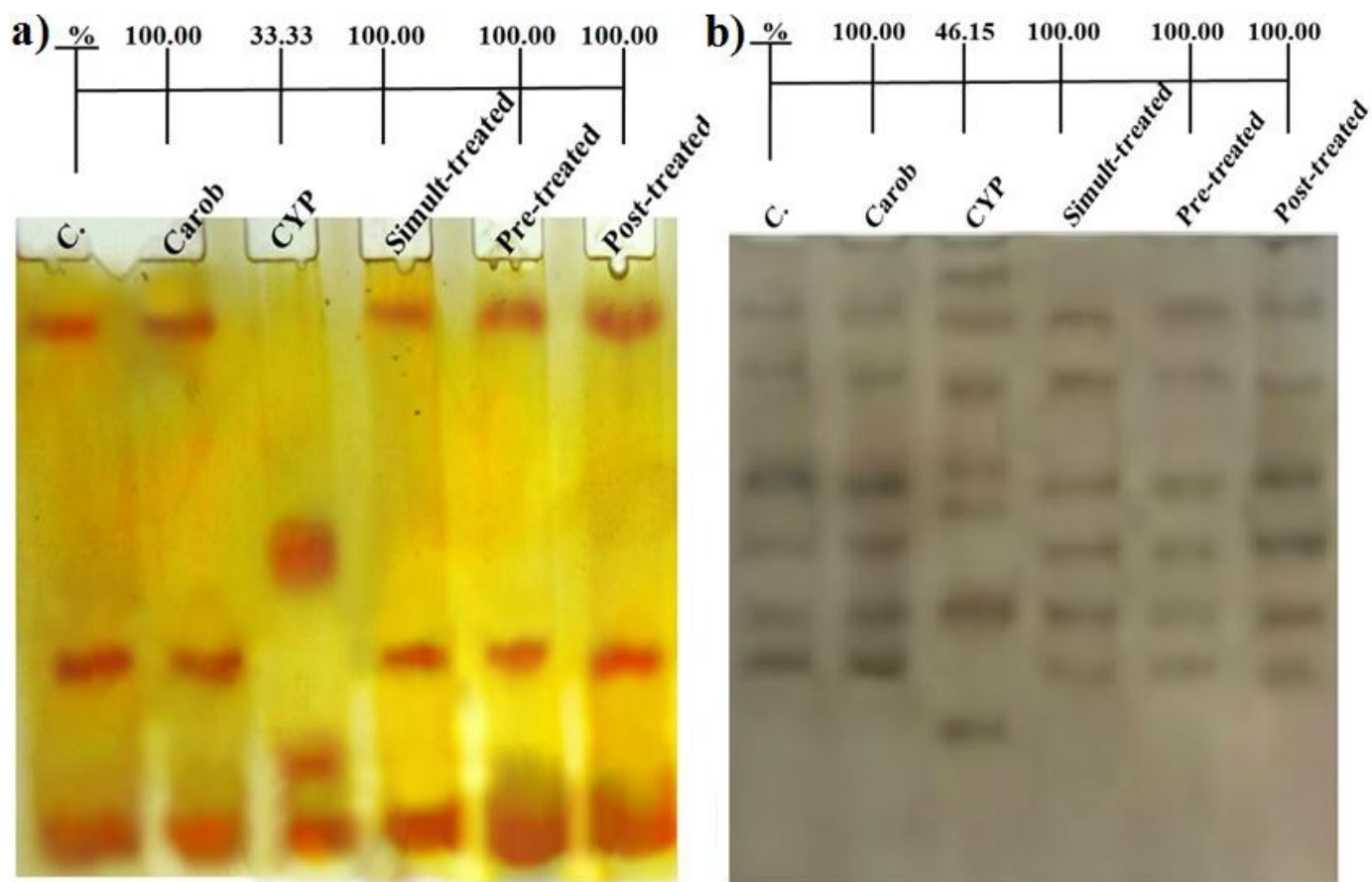

Fig. 6: Electrophoretic zymogram showing the curative effect of aqueous carob extract against cyclophosphamide induced alterations on a) catalase pattern and b) peroxidase pattern in bone marrow of rats.

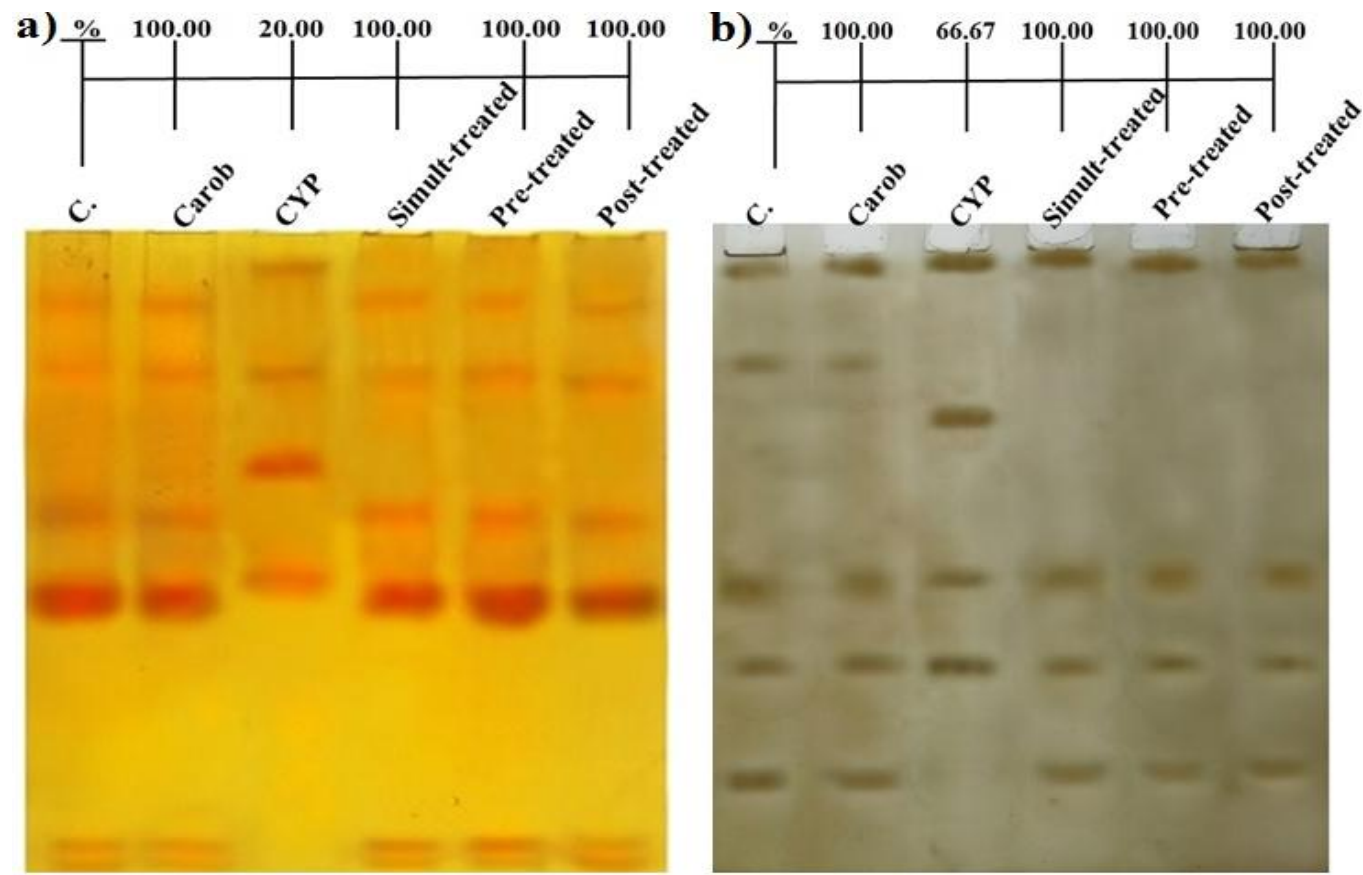

Fig. 7: Electrophoretic zymogram showing the curative effect of aqueous carob extract against cyclophosphamide induced alterations on a) catalase pattern and b) peroxidase pattern in spleen tissue of rats. 


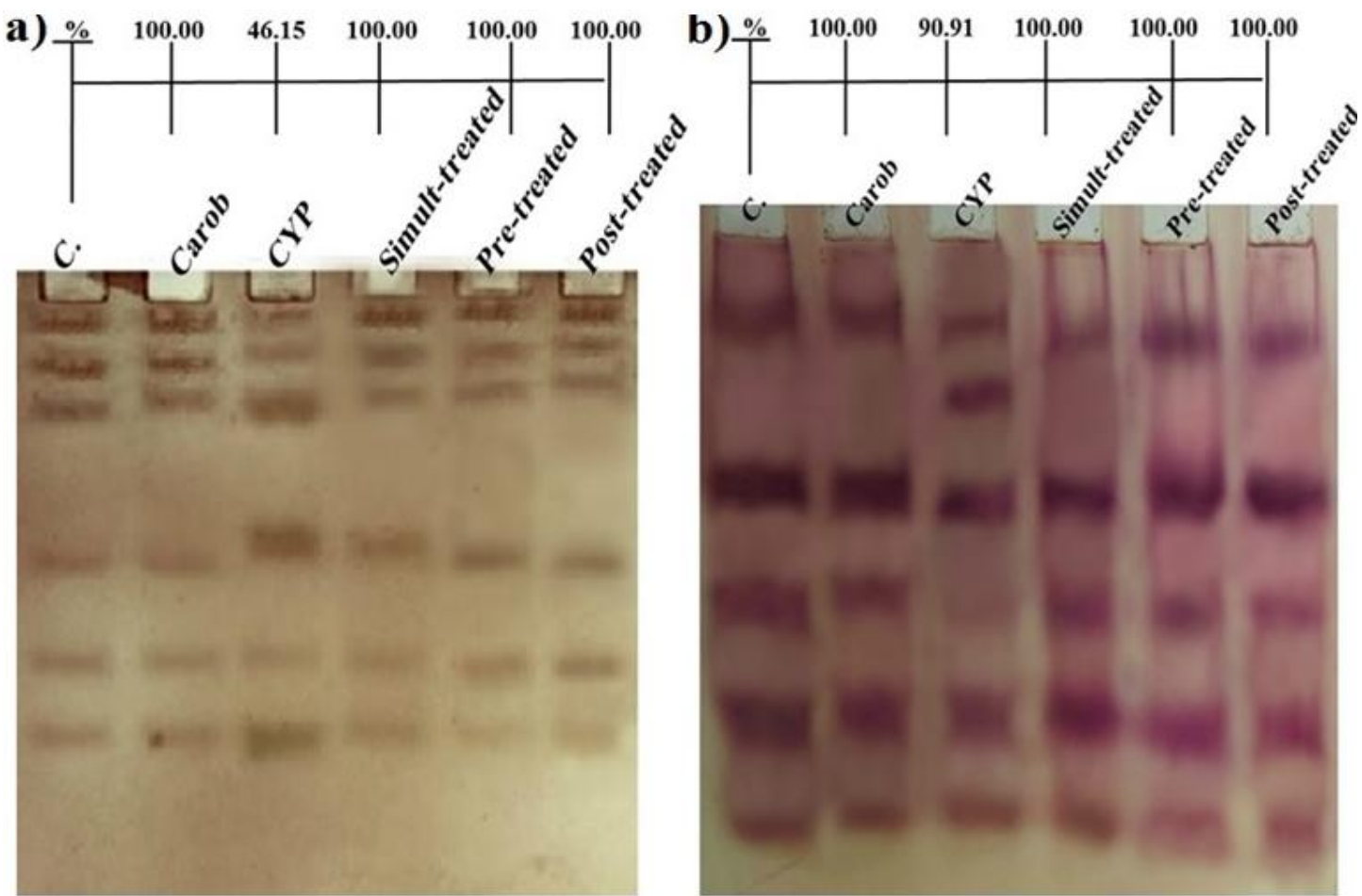

Fig. 8: Electrophoretic zymogram showing the curative effect of aqueous carob extract against cyclophosphamide induced alterations on a) $\alpha$-esterase pattern and b) $\beta$-esterase pattern in bone marrow of rats.

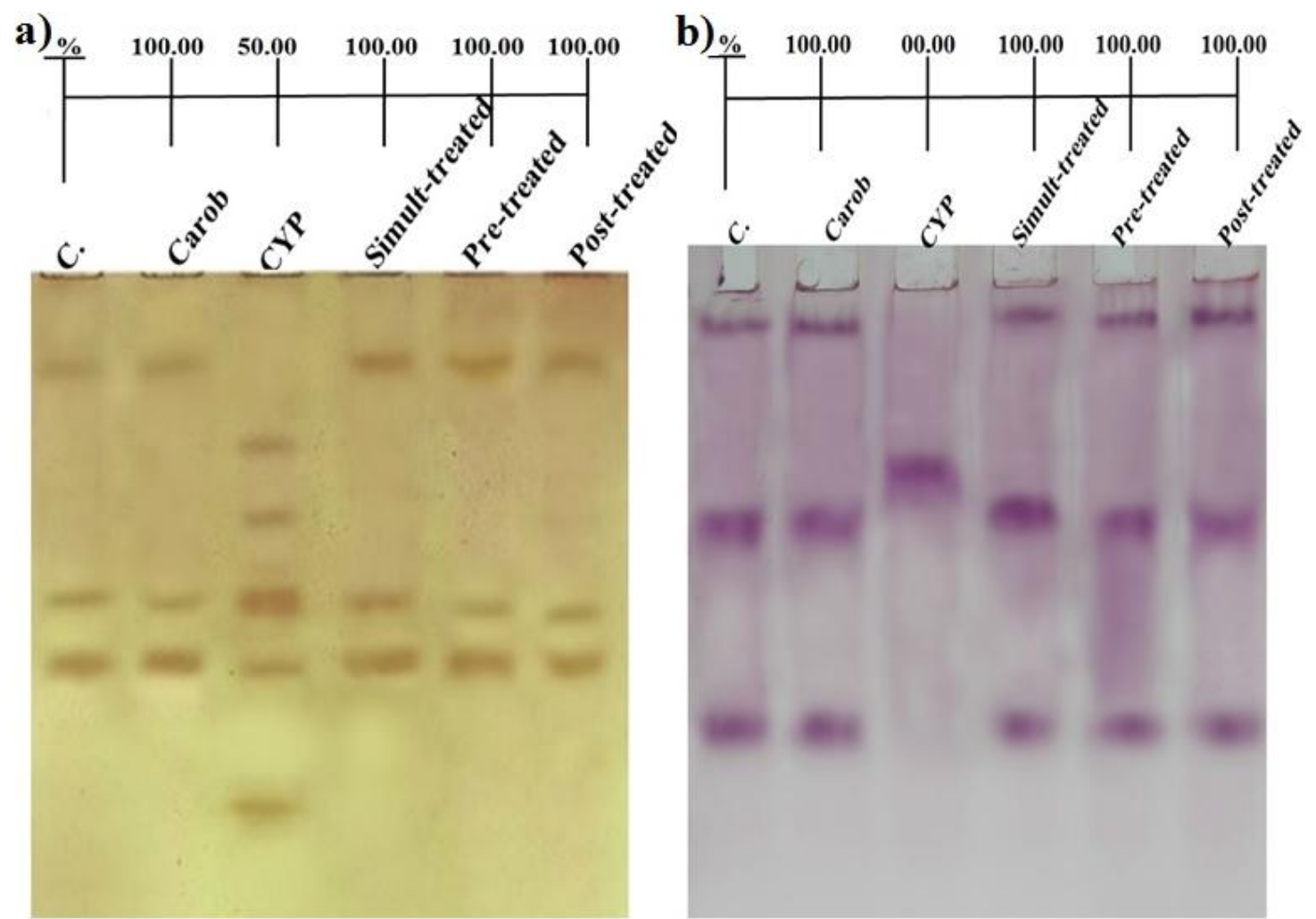

Fig. 9: Electrophoretic zymogram showing the curative effect of aqueous carob extract against cyclophosphamide induced alterations on a) $\alpha$-esterase pattern and b) $\beta$-esterase pattern in spleen tissue of rats. 

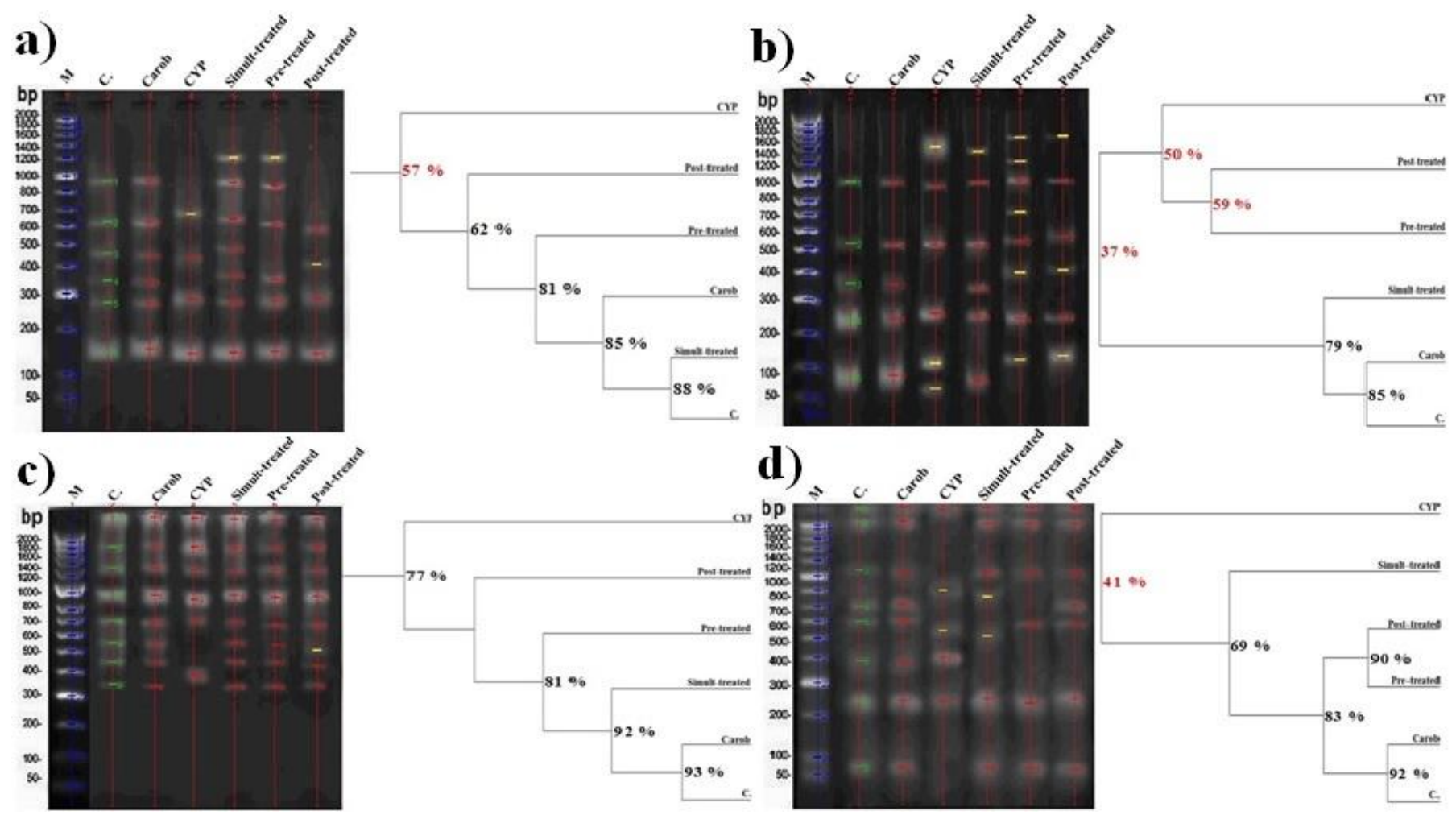

Fig. 10: Genomic DNA pattern showing the alterations induced by cyclophosphamide in spleen tissue and the curative effect of aqueous carob extract using the random primers a) OPA-04 and OPA-05, b) OPA-07 and OPA-10, c) OPA-11 and OPA-12 and d) OPA-14 and OPA-15.

\section{Genomic DNA pattern}

As graphically illustrated in Fig. 10a, it was verified that CYP caused various deleterious mutagenicity represented qualitatively by disappearance of 3 normal bands with existence of one abnormal band (Rf 0.34; Mwt $1168.30 \mathrm{Bp}$ ). In addition, it caused quantitative variation represented by increasing quantity of the bands that identified at normal relative mobilities with the primers OPA-04 and OPA- 05 . The amplicon with the primers OPA-07 and OPA-10 (Fig. 10b) revealed that CYP exerted its mutagenic effect qualitatively by absence of 2 normal band with existence of 3 abnormal bands (Rfs 0.15, 0.81 and 0.89; Mwts 1724.47, 710.09 and $626.46 \mathrm{Bp}$, respectively). With the primers OPA-11 and OPA-12 (Fig. 10c), the qualitative alterations were represented by disappearance of 2 normal band without existence of abnormal bands in the CYP-treated group. Moreover, CYP caused variation at the quantitative level represented by elevation quantity of the band identified at Rf 0.12 and Mwt 1932.77 Bp. With the primers OPA-14 and OPA-15 (Fig. 10d), the results revealed that CYP caused various deleterious mutagenicity represented qualitatively by disappearance of 5 normal bands with existence of 2 abnormal band (Rf 0.29 and 0.42; Mwts 1400 and $1142.68 \mathrm{Bp})$. According to averages of the SI \% values with all primers with respect to control, the lowest SI \% value was noticed in CYP-treated group (SI \% 48.48) and the carob extract increased the SI $\%$ values in simult-treated, pre-treated and post-treated groups (SI \% values 74.50, 70.88 and 68.13, respectively) through restoring the absent normal bands and hiding the abnormal ones.

\section{DISCUSSION}

Blood is body fluid responsible for regulating the vital body functions through transportation of oxygen and nutrients to different tissues (Savithri et al., 2010). The haematological indices provide with crucial information for evaluation of vitality of the different tissues (Promise et al., 2014). During the current study, CYP caused significant reduction in all hematological measurements. This was in accordance with Stalin and Kumar (2013) who reported that CYP exhibits profound adverse effects on blood and bone marrow due to interaction of its active metabolites with the haematopoeitic tissues which subsequently cause depression of the haematopoeitic activities. Furthermore, CYP caused decrease in these measurements due to immunosuppressive effect of CYP and retarded haematopoeisis and /or interaction of the active metabolic CYP products with proteins of the erythrocytes membranes leading to elevation of RBCs destruction rate and decrease in $\mathrm{HB}$ synthesis and hence decline in MCV, MCH and MCHC (Promise et al., 2014).

CYP caused decline in WBCs. This was in agreement with Mitsuoka et al. (1976) who suggested that CYP caused destruction of short-lived suppressor $\mathrm{T}$ cells in immune regulatory systems. Also, it caused a depletion of lymphocytes and this was in agreement with Uitdehaag et al. (1989) who documented that lowering count of the blood cells may be attributed to immunotoxic CYP effect on all lymphoid cells. Moreover, it may refer to role of CYP which stimulates rapid elimination of 
lymphocytes from lymphoid tissue in thymus-dependent areas of the spleen tissue (Ben-Hur et al., 2002). In addition, it was noticed that CYP caused significant decline in all peripheral blood cells count (neutrophil, monocytes and eosinophil). These findings were supported by Michiyuki et al. (2007) who postulated that CYP caused decline in count of the differential blood cells due to CYP effect on the bone marrow which is the most sensitive target during the immunosuppression therapy with CYP. Subsequently, this leads to loss of stem cells and inability of bone marrow to regenerate new blood cells. In the present study, the antihaematotoxic effect of aqueous carob extract against CYPinduced haematotoxicity in rats was investigated. The carob extract is rich in various polyphenolic compounds (Makris and Kefalos, 2004). Presence of these polyphenols contributes significant role in improving the immune system thereby fighting against numerous infectious diseases (Jones, 1996). It significantly increased levels of the haematological indices thereby reversing/ameliorating the anaemic condition induced by CYP. This might refer to reversal of bone marrow depression thus improving haematopoeitic activity of the cells and hence improvement of integrity of erythrocyte membranes through the antioxidant potential of the extract, thereby reducing haemolysis. In addition, the extract may enhance protein synthesis which leads to increase in $\mathrm{HB}$ level and consequently results to increase in $\mathrm{MCH}$ and $\mathrm{MCHC}$ and increase the RBCs count resulting in an increase in MCV. The results indicate that there is significant increased all peripheral blood cells count with respect to CYPtreated group. This might refer to restoration of bone marrow activity in all carob treated groups and stimulation of the immune response that subsequently leads to significant increase in the count of these differential blood cells.

During the current study, CYP caused decrease in the TAC level in bone marrow and spleen. This was in accordance with Schlezinger et al. (1999) who suggested that CYP affected activity of antioxidant enzymes due to the different modification in protein structure of these enzymes through the reactive CYP metabolites which exhibited inhibitory effect on biosynthesis of enzyme molecules. Also, CYP reduced activity of the antioxidant enzymes due to oxidation of thiol group in the active center of these enzymes by acrolein (active CYP metabolite) (Gilbert, 1984). CYP is associated with induction of oxidative stress by the generation of free radicals (Dumontet et al., 2001). In consequence, inhibition of these enzymes leads to further peroxidation reaction and enhanced LPO level and hence reduction of total antioxidant status (Stankiewicz and Skrzydlewska, 2005). The carob is rich in various effective polyphenolic compounds such as gallic acid, epigallocatechin-3-gallate and epicatechin-3gallate (Corsi et al., 2002) and according to schedule of the treatment, it was not possible to determine whether the protection offered by the extracts was related to a reduction in the efficacy of CYP or to a direct effect on the cells themselves.

Rats are the most suitable model of experimental animals for study of CYP toxicity at the histopathological level (Abd-Allah et al., 2005). During the current study, CYP caused lesions in spleen tissue associated with ischaemia and fibrosis in the red pulps. This was in accordance with Hermenean et al. (2008) who noticed appearance of red and white pulp and most of lymphocyte populations in different stages of apopthosis or necrobiosis. This might refer to the qualitative and quantitative recovery in CYPtreated rats. It was noticed that hematopoesis occurred in spleen tissue of CYP-treated groups which were treated with aqueous carob extract. This might be attributed to the explanation suggested by Litam et al. (1999) who emphasized that structures of the spleen has capacity to recover and resuming the normal morpho-functionality of the immune system after the treatment with CYP. Moreover, the spleen takes part of the organism to recover the normal structures affected CYP through reactivation of hematopoesis. The carob extract stimulated recovery of the spleen tissue.

Electrophoresis is standard technique for separating, identifying and quantifying of different proteins based on their physical properties such as the net charge (positive or negative), size and shape of the protein molecules (Shah et al., 2010). Each band is made up of group of the individual proteins which are characterized by independent metabolic properties (O'Connell et al. 2005). The abnormalities in the native protein pattern are completely related to the physiological and individual conditions (França et al. 2011). The electrophoretic identification and quantification of the protein fractions enable the researchers to determine the altered protein pattern which may reflect responses to changes in homeostasis or disease (Ahmadi-Hamedani et al. 2014). During the current study, CYP caused alterations in the native protein pattern. This was in accordance with Omidvar et al. (2011) who reported that the alterations in the native protein may refer to interaction of CYP with proteins. Moreover, AguilarMahecha et al. (2002) suggested that the electrophoretic alterations may refer to effect of CYP on RNA transcripts, altering their amounts, localization or translation. In addition, these alterations may be attributed to role of the alkylating activity of CYP which preferentially bind to matrix proteins and matrixassociated DNA (Fernandes and Catapano, 1995). Also, the modifications in the overall native protein pattern and the changes in its composition may correlate with alterations in DNA organization, leading to changes in DNA function and protein expression (Harrouk et al., 2000). Lipids are not only membrane components, but also represent the important components of chromosomes, chromatin and the nuclear matrix (Struchkov et al., 2002). In the current experiment, CYP caused abnormalities in the electrophoretic lipoprotein pattern. This may refer to effect of the acrolein (CYP metabolite), which attack the lipid portion through inducing formation of the reactive oxygen species and peroxidation reaction (Sulkowska et al., 1998). The carob extract exhibit antioxidant properties through reducing the oxidation process. This might be due to presence of the phenolic compounds which scavenge the free radicals and hence reduce the peroxidation reaction (Kumazawa et al., 2002).

During the present study, CYP caused alterations in electrophoretic CAT pattern. This may be due to binding CYP 
with native macromolecules inducing secondary structural changes in the enzyme (Mansouri et al., 2013). In addition, the alterations in CAT pattern may refer to effect of CYP on thymus and spleen through inducing immunosuppression (Wei et al., 2011).

The current study presented that CYP caused alterations in the electrophoretic GPx pattern. This was in agreement with Codrington et al. (2007) who reported that CYP induced oxidative stress and lipid peroxidation that might be reduced by GPx4. It induced changes in the amount of all known forms of the antioxidant GPx enzyme especially GPx4. This refers to the full effect of CYP on expression of GPx4 resulting in an increase in chromatin-bound GPx4 as well as matrix-specific increased expression and elevation of GPx4 immunoreactivity in CYPtreated rats. Carob extract exhibited antioxidant effect and minimized the electrophoretic alterations in CAT and GPx patterns. This may be attributed due to presence of total polyphenols, total flavonols (Kumazawa et al., 2002), proanthocyanidins and hydrolysable tannins (Avallone et al., 1997).

The spleen esterase is considered to be a nonspecific esterase. It appears that in the spleen fraction only one esterase functions in the degradation and inactivation of endotoxin (Skarnes et al., 1968). The alpha-naphthyl acetate esterase enzyme has been considered to be a marker of $\mathrm{T}$ lymphocytes in peripheral blood and tissue sections, because the enzyme was not found in B lymphocytes (Beya et al., 1986). During the current study, CYP caused alterations in the electrophoretic esterase pattern. This was in accordance with Sakthivel and Guruvayoorappan (2015) who documented that $\alpha$-esterase positive cells were also found to be reduced drastically in CYP-treated group. The carob extract with its active constituents prevented effect of CYP on esterase enzyme due to its potential on stem cell proliferation and differentiation.

CYP belongs to the oxazaphosphorines group which exhibits cytotoxic and mutagenic properties (Hamideh et al., 2015). It exhibited the cytotoxic effect as a result of its interaction with DNA. Subsequently, this leads to defective DNA, abnormal cell function and hence cell death (Lee and Schmitt, 2003). During the current study, CYP caused changes in the genomic DNA pattern. This was in accordance with Codrington et al. (2007) who demonstrated significantly that alkylating agent alters the protein profile of the nuclear matrix. Moreover, the changes in composition of general proteins in the nuclear matrix may subsequently lead to altering the composition of the nuclear matrix associated with DNA disorganization and hence altering nuclear function (Chen et al., 2001). The natural compounds with antioxidant properties can exhibit the antioxidant efficiency in a dose dependent manner (Paolini et al., 2003). These compounds can prevent or reduce the DNA oxidation without decreasing effectiveness of chemotherapeutic compounds. In addition, they protect normal cells against the adverse side-effects of some chemotherapeutic agents (Popov et al., 2011). Scavenging of the free radicals as hydroxyl radical which is the major cause of LPO by extract may be attributed to their phenolic compounds which are the primal source of antioxidant ability of carob (Kumazawa et al., 2002; Ahmed, 2010).

\section{CONCLUSIONS}

The study concluded that carob pods extract exhibited scavenging activities against oxidative stress induced by CYP in spleen and bone marrow. It restored all the hematological measurements that reduced in CYP treated group. Moreover, it increased the SI \% value in the native electrophoretic protein, lipoprotein, calcium moieties of protein and isoenzymes (CAT, GPx, $\alpha$ - and $\beta$-EST) in spleen and bone marrow through restoring the absent normal bands and hiding the abnormal ones. Also, it maintained integrity of the genomic DNA in spleen tissue.

\section{Financial support and sponsorship: Nil.}

Conflict of Interests: There are no conflicts of interest.

\section{REFERENCES}

Abd-Allah AR, Gado IS, Al-Majed AAA, Al-Yahya AA, AlShabanah OA. Protective effect of taurine against cyclophosphamideinduced urinary bladder toxicity in rats. Clin Exp Pharmacol Physiol. 2005 ;32, 167-72.

Abdul Karim A, Azlan A. Fruit pod extracts as a source of nutraceuticals and pharmaceuticals. Molecules. 2012;17, 11931-11946.

Aguilar-Mahecha A, Hales BF, Robaire B. Chronic cyclophosphamide treatment alters the expression of stress response genes in rat male germ cells. Biol Reprod. 2002 ; 66, 1024-1032.

Ahmad A, Maheshwari V, Ahmad A, Saleem R, Ahmad R. Observation of esterase-like-albumin activity during N'- nitrosodimethyl amine induced hepatic fibrosis in a mammalian model. Maced J Med Sci. $2012 ; 5(1), 55-61$.

Ahmadi-Hamedani M, Ghazvinian K, Kokhaei P, Barati M, Mahdavi A. Comparison of effects of age and sex on serum protein electrophoretic pattern in one-humped camels (Camelus dromedarius) in Semnan, Iran. Open Vet J. 2014 ; 4, 4-8.

Ahmed MM. Biochemical studies on nephroprotective effect of carob (Ceratonia siliqua L.) growing in Egypt. Nat Sci. 2010 ; 8, 41-47.

Angulo I, Heras FG, Garcia-Bustos JF, Gargallo D, MunozFernandez MA, Fresno M. Nitric oxide-producing CD11b(+)Ly-6G(Gr$1)(+) C D 31($ ERMP12)(+) cells in the spleen of cyclophosphamide treated mice: Implications for T-cell responses in immunosuppressed mice. Blood. $2000 ; 95,212-220$.

Avallone R, Cosenza F, Farina F, Baraldi C, Baraldi M. Extraction and purification from Ceratonia siliqua of compounds acting on central and peripheral benzodiazepine receptors. Fitoterapia. $2002 ; 73$, 390-396.

Avallone R, Plessi M, Baraldi M, Monzani A. Determination of chemical composition of carob (Ceratonia siliqua): Protein, fat, carbohydrates and tannins. J Food Compost Anal. 1997 ; 10, 166-172.

Ayhanci A, Yaman S, Appak S, Gunes S. Hematoprotective effect of seleno-L-methionine on cyclophosphamide toxicity in rats. Drug Chem Toxicol. 2009 ; 32(4), 424-842.

Banchroft JD, Stevens A, Turner DR. 1996. Theory and Practice of Histological Techniques. Fourth Ed. Churchil Livingstone, New York, London, San Francisco, Tokyo.

Barker DL, Hansen MS, Faruqi AF, Giannola D, Irsula OR, Lasken RS, Latterich M, Makarov V, Oliphant A, Pinter JH. Two Methods of Whole-Genome Amplification Enable Accurate Genotyping Across a 2320-SNP Linkage Panel. Genome Res. 2004 ; 14(5), 901-907. 
Ben-Hur H, Kossoy G, Zndbank J, Zusman I. Response of the immune system of mammary tumor bearing rats to cyclophosphamide and soluble low molecular-mass tumor-associated antigens: rate of lymphoid infiltration and distributions of T lymphocytes in tumors. Int J Mol Med. 2002; 9, 425-430.

Beya MF, Miyasaka M, Dudler L, Ezaki T, Trnka Z. Studies on the differentiation of $\mathrm{T}$ lymphocytes in sheep: 1. Two monoclonal antibodies that recognize all ovine T lymphocytes. Immunol. $1986 ; 57$, 115-121.

Bradford MM. A rapid and sensitive method for the quantitation of microgram quantities of protein utilizing the principle of protein-dye binding. Anal Biochem. 1976; 72, 248-254.

Chen JL, Guo SH, Gao FH. Nuclear matrix in developing rat spermatogenic cells. Mol Reprod Dev. 2001; 59, 314-321.

Codrington AM, Hales BF, Robaire B. Chronic cyclophosphamide exposure alters the profile of rat sperm nuclear matrix proteins. Biology and Reproduction. 2007; 77, 303-311.

Corsi L, Avallone R, Cosenza F, Farina F, Baraldi C, Baraldi M. Antiproliferative effects of Ceratonia siliqua L. on mouse hepatocellular carcinoma cell line. Fitoterapia. 2002; 73, 674-684.

Darwesh OM, Moawad H, Barakat OS, Abd El-Rahim WM. Bioremediation of textile reactive blue azo dye residues using nanobiotechnology approaches. Research Journal of Pharmaceutical, Biological and Chemical Sciences. 2015; 6(1), 1202- 1211.

Dommels YEM, Butts CA, Zhu S, Davy M, Martell S, Hedderley D, Barnett MPG, McNabb WC, Roy NC. Characterization of intestinal inflammation and identification of related gene expression changes in mdrla(-/-) mice. Genes Nutr. 2007; 2, 209-223.

Dumontet C, Drai J, Thieblemont C, Hequet O, Espinouse D, BouaWa F, Salles G, Coiffier B. The superoxide dismutase content in erythrocytes predicts short-term toxicity of high-dose cyclophosphamide. Br J Haematol. 2001 ; 112, 405-409.

Fernandes DJ, Catapano CV. The nuclear matrix as a site of anticancer drug action. Int Rev Cytol. 1995; 162A, 539-576.

França RT, Costa MM, Martins DB, Pagnoncelli M, Leal ML, Mazzanti CM, Palma HE, Kunert CP, Paim FC, dos Anjos Lopes ST. Protein profile of buffaloes of different ages. Acta Sci Vet. 2011;39, 995 999.

Gilbert HF. Redox control of enzyme activities by thiol/disulfide exchange. Methods Enzymol. 1984; 107, 330-51.

Groopman JE, Itri LM. Chemotherapy-induced anemia in adults: incidence and treatment. J Natl Cancer Inst. 1999; 91, 1616-1634.

Hamideh D, Nahid AJ, Zahra AJ, Houshang J, Majid AJ, Reza AJA. Antioxidant effect and protects the Turnip root on liver enzyme changes in rats undergoing chemotherapy with cyclophosphamide. Research Journal of Fisheries and Hydrobiology. 2015 ; 10(10), 1-4.

Harrouk W, Codrington A, Vinson R, Robaire B, Hales BF. Paternal exposure to cyclophosphamide induces DNA damage and alters the expression of DNA repair genes in the rat preimplantation embryo. Mutat Res. 2000; 461, 229-241.

Hermenean A, Ardelean A, Craciun C. Spleen structural damages and tissular biochemical parameters disturbances at wistar rats after chimiotherapy administration. Studia Universitatis "Vasile Goldiş", Seria Ştiințele Vieţii (Life Sciences Series). 2008 ; 18, $255-258$.

Jones FA. Herbs useful plants their role in history and today. European journal Gastroentero Hepatol. 1996; 8, 1227-1231.

Koracevic D, Koracevic G, Djordjevic V, Andrejevic S, Cosic V. Method for the measurement of antioxidant activity in human fluids. J Clin Pathol. 2001; 54, 356-361.

Kumazama S, Tanaguchi M, Suzuki Y, Shimura M, Kwon MS, Nakayama T. Antioxidant activity of polyphenols in carob pods. J Agric Food Chem. 2002 ; 50, 373-377.

Laemmli UK. Cleavage of structural proteins during the assembly of the head of Bacteriophage T4. Nature. 1970;227, 680-685.

Lee S, Schmitt CA. Chemotherapy response and resistance. Curr Opin Genet Dev. 2003; 13, 63-69.

Litam P, Friedman H, Loughran J. Splenic extramedullary hematopoiesis in a patient receiving intermittently administered granulocyte colony-stimulating factor. Annals of Internal Medicine. 1993; 118(12), 954-955.

Makris DP, Kefalos P. Carob pods (Ceratonia silique L.) as a source of polyphenolic antioxidants. Food Technol Biotechnol. 2004; 42, 105-108.

Mansouri M, Pirouzi M, Saberi MR, Ghaderabad M, Chamani J, Investigation on the Interaction between cyclophosphamide and lysozyme in the presence of three different kind of cyclodextrins: determination of the binding mechanism by spectroscopic and molecular modeling techniques. Molecules. 2013; 18, 789-813.

McKallip RJ, Lombard C, Martin BR, Nagarkatti M, Nagarkatti PS. Delta(9)-tetrahydrocannabinol-induced apoptosis in the thymus and spleen as a mechanism of immunosuppression in vitro and in vivo. $\mathrm{J}$ Pharmacol Exp Ther. 2002; 302(2), 451-465.

Michiyuki K, Takashi A, Megumi T, Hiroyuki H, Kazuhisa F. Investigation of post-weaning changes in immunological parameters in male rats. Toxicology. 2007; 232, 119-131.

Mitsuoka A, Mitsuo B, Morikowa S. Enhancement of delayed hypersensitivity by depletion of suppressor T cells with cyclophosphamide in mice. Nature. 1976; 262, 77-79.

Muenchen HJ, Pienta KJ. The role of the nuclear matrix in cancer chemotherapy. Crit Rev Eukaryot Gene Expr. 1999; 9, 337-343.

Nei M, Li WS. Mathematical model for studing genetic variation in terms of restriction endonuclease. Proc. Natl. Acad. Sci., USA. $1979 ; 76,5269-5273$.

Nygaard UC, Løvik M. Blood and spleen lymphocytes as targets for immunotoxic effects in the rat--a comparison. Toxicology. 2002 ; 174(3), 153-161.

O'Connell TX, Horite TJ, Kasravi B. Understanding and interpreting serum protein electrophoresis. Am Fam Physician. 2005; 71, 105-112.

Ohkawa H, Ohishi N, Nagi K. Assay of lipid peroxides in animal tissue by thiobarbituric acid reaction. Anal Biochem. $1979 ; 95$, 351-358

Omidvar Z, Parivar K, Sanee H, Amiri-Tehranizadeh Z, Baratian A, Saberi MR, Asoodeh A, Chamani JK. Investigations with Spectroscopy, Zeta Potential and Molecular Modeling of the NonCooperative Behaviour between Cyclophosphamide Hydrochloride and Aspirin upon Interaction with Human Serum Albumin: Binary and Ternary Systems from the View Point of Multi-Drug Therapy. J Biomol Struct Dyn. $2011 ; 29,181-206$.

Paolini M, Abdel-Rahman SZ, Sapone A, Pedulli GF, Perocco P, Cantelli-Forti G, Legator MS. $\beta$-carotene: A cancer chemopreventive agent or a cocarcinogen?. Mutat Res. 2003 ; 543, 195-200.

Patel KK, Toppo FA, Singour PK, Chaurasiya PK, Rajak H, Pawar RS. Phytochemical and pharmacological investigations on aerial parts of Nelumbo nucifera Gaertn. For haematopoietic activity. Indian Journal of Natural Products and Resources. 2012; 3(4), 512 - 517.

Popov B, Georgieva S, Gadjeva V. Modulatory effects of total extract of Haberlea rhodopensis against the cyclophosphamide induced genotoxicity in rabbit lymphocytes in vivo. Trakia Journal of Sciences. 2011; 9 (1), 51-57.

Promise N, Agomuo EN, Uloneme GC, Egwurugwu JN, Omeh YN, Nwakwuo GC. Effect of Phyllanthus amarus leaf extract on alterations of haematological parameters in Salmonellae typhi infested wistar albino rats. Scientific Research and Essays. 2014 ; 9(1), 7-12.

Rapley R. 1998. Polymerase chain reaction, in Molecular Biomethods Handbook (Rapley, R. and Walker, J. M., ed.), Humana, Totowa, NJ, pp. 305-325.

Rescigno A, Sanjust E, Montanari L, Sollai F, Soddu G, Rinaldi AC, Oliva S, Rinaldi A. Detection of laccase, peroxidase and polyphenol oxidase on a single polyacrylamide gel electrophoresis. Anal Lett. 1997 ; 30(12), 2211-2220.

Rtibi K, Jabri MA, Selmi S, Souli A, Sebai H, El-Benna J, Amri M, Marzouki L. Gastroprotective effect of carob (Ceratonia siliqua L.) against ethanol-induced oxidative stress in rat. BMC Complementary and Alternative Medicine. 2015; 15, 292.

Ryu HS, Kim JH, Kim HS. Effect of a Plant Water Extract Mixture (Ixeris sonchifolia Hance, Oenanthe javanica, Fagopyrum 
esculentum Moench, Hizikia fusiforme, Zingiber officinale Roscoe) on Mouse Immune Cell Activation. Korean J Food Nutr. 2007 ; 20, 74-78. Ryu HS, Kim HS. Effects of Job's Tear (Yul-Moo) Extracts on Mouse Immune Cell Activation. J Korean Diet Assoc. 2005 ; 11, 44-50.

Sakthivel KM, Guruvayoorappan C. Acacia ferruginea inhibits cyclophosphamide-induced immunosuppression and urotoxicity by modulating cytokines in mice. J Immunotoxicol. 2015 ; 12(2), 154-163.

Savithri Y, Sekhar PR, Doss PJ. Changes in haematological profiles of albino rats under chlorpyrifos toxicity. Int J Pharma Bio Sci. $2010 ; 1,1-7$.

Schlezinger JJ, White RD, Stegeman JJ. Oxidative inactivation of cytochrome P-450 1A (CYP1A) stimulated by 3,3',4,4'tetrachlorobiphenyl: production of reactive oxygen by vertebrate CYP1As. Mol Pharmacol. 1999; 56(3), 588-597.

Schwenke K, Coslar S, Miihlensiepen H, Altman KI, Feinendegen LE. Lipid peroxidation in microsomes of murine bone marrow after low-dose $\gamma$-irradiation. Radiat Environ Biophys. 1994 ; 33, 315323.

Shah PI, Bhatt PA, Patel PS, Ghori VL, Vaghela PD. Study of Electrophoretic pattern in serum of Multiple Myeloma Patients. Int $\mathbf{J}$ Pharm \& Health Sci. 2010 ; 1(2), 116-131.

Siciliano MJ, Shaw CR. 1976. Separation and visualization of enzymes on gels, in Chromatographic and Electrophoretic Techniques, Vol. 2, Zone Electrophoresis, Smith, I., Ed., Heinemann, London, p. 185.

Skarnes R, Rutenburg S, Fine J. Fractionation of an esterase from calf spleen implicated in the detoxification of bacterial endotoxin. Exp Biol Med (Maywood). 1968 ; 128 (1), 75-80.

Sobel DO, Ahvazi B, Jun HS, Chung YH, Yoon JW. Cyclophosphamide inhibits the development of diabetes in the diabetesprone BB rat. Diabetologia. 2000; 43(8), 986-994.

Stalin S, Kumar PS. Immunostimulatory Effect of Aqueous Extract of Leucas aspera in Cyclophosphamide Induced Immunosuppressive Mice. International Journal of PharmTech Research. 2013; 5 (3), 910-914.

Stankiewicz A, Skrzydlewska E. Amifostine Antioxidant Effect on Serum of Rats Treated with Cyclophosphodamide. Polish Journal of Environmental Studies. 2005; 14 (3), 341-346.
Struchkov VA, Strazhevskaya NB, Zhdanov RI. Specific natural DNA bound lipids in post-genome era. The lipid conception of chromatin organization. Bioelectrochemistry. $2002 ; 56,195-198$.

Subramaniam HN, Chaubal KA. Evaluation of intracellular lipids by standardized staining with a Sudan black B fraction. J Biochem Biophys Methods. 1990 ; 21(1), 9-16.

Sulkowska M, Sulkowski S, Skrzydlewska E, Farbiszewski R. Cyclophosphamide-induced generation of reactive oxygen species. Comparison with morphological changes in type II alveolar epithelial cells and lung capillaries. Exp Toxicol Pathol. 1998 ; 50, 209-220.

Uitdehaag BM, Nillesen WM, Hommes OR. Long-lasting effects of cyclophosphamide on lymphocytes in peripheral blood and spinal fluid. Acta Neurol Scand. 1989 ; 79(1), 12-17.

Vadhan-Raj S. Management of chemotherapy-induced thrombocytopenia: current status of thrombopoietic agents. Semin Hematol. 2009 ; 46(1,2), S26-32.

Wei XJ, Hu TJ, Chen JR, Wei YY. Inhibitory effect of carboxymethylpachymaran on cyclophosphamide-induced oxidative stress in mice. Int J Biol Macromol. 2011 ; 49(4), 801-805.

Zacharia SY, Kakati VS. Characterisation of vitellogenin and vitellin of Fenneropenaeus merguiensis (De Man). Indian J Fish. 2004; 51 (3), 255-263.

Zhao CH, Li QF, Zhao Y, Niu JW, Li ZX, Chen JA. Changes of nuclear matrix proteins following the differentiation of human osteosarcoma MG-63 cells. Genomics Proteomics Bioinformatics. 2006; 4, $10-17$.

\section{How to cite this article:}

Elhalim SAA, Sharada HM, Abulyazid I, Aboulthana WM, Elhalim STA. Ameliorative Effect of Carob Pods Extract (Ceratonia siliqua L.) against Cyclophosphamide Induced Alterations in Bone Marrow and Spleen of Rats. J App Pharm Sci, 2017; 7 (10): 168181. 